Bangladesh J. Bot. 49(1): 39-46, 2020 (March)

\title{
POLLEN MORPHOLOGY OF CHESTNUT CULTIVARS IN SOUTHERN CHINA BY USING SCANNING ELECTRON MICROSCOPE
}

\author{
Huan Xiong, De-Yi Yuan, Ya Chen, Genhua Niu and Feng Zou* \\ The Key Lab of Non-wood Forest Products of Forestry Ministry, Central South University of \\ Forestry and Technology, Changsha 410004, Hunan, P. R. China
}

Keywords: Pollen morphology, Chestnut, Pollen axis length, Equatorial width, Colpus length

\begin{abstract}
The morphological characteristics of pollen grains of 16 cultivars belonging to two species of the genus Castanea (Castanea mollissima and $C$. henryi) collected from southern China were observed by using scanning electron microscope (SEM). The length of polar axis (PL), the equatorial diameter (ED), the length of colpus (CL) of grain, $\mathrm{P} / \mathrm{E}$ ratio (polar axis to equatorial diameter), $\mathrm{P} / \mathrm{C}$ ratio (polar axis to colpus length), and $\mathrm{C} / \mathrm{E}$ ratio (colpus length to equatorial diameter) were measured and their variations were compared among studied taxa. The result of this study indicated that chestnut pollen grain was a tricolporate in aperture type, and aperprolate type in equatorial view. The morphological characteristics were mainly represented by PL, ED and CL as revealed by principal components analysis, which accounted for $99.56 \%$ of the total variations. The cluster analysis by the UPGMA tree divided the taxa into three groups and showed a great morphological affinity among the 16 cultivars.
\end{abstract}

\section{Introduction}

Chestnut has been placed in the family of Fagaceae which is monoecious, wind-pollinated and self-incompatible (Mckay 1942, Bounous and Marinoni 2005). In China, this species is economically important for timber and nut production. Three species in this genus are native to China, including two main economic species, namely: Castanea mollissima Blume and C. henryi Rehd. \& Wils (Huang 1998). C. mollissima is widely distributed in Jilin, Hebei, Shangdong, Sichuan, Hubei, Anhui, Jiangsu, Hainan Island, Taiwan, and Yunnan Provinces (Zou et al. 2014). However, $C$. henryi is distributed in the southern China, especially in Fujian, Zhejiang and Hunan Provinces (Huang 1998, Fan et al. 2015, Xiong et al. 2018).

The pollen grains have a definite shape, size, color and structure for each species, genus and family, and these characteristics are useful for systematic botany (Lee et al. 2008, Mert 2010). In the study of chestnut pollens, Lee and Kim (2004) reported that chestnut (Castanea spp.) pollens were significantly different among interspecies and inter-cultivars in pollen morphology. Mert and Soylu $(2006,2007)$ described the flower and stamen structures of four male-fertile and two male-sterile chestnut cultivars by scanning electron and light microscopes. Liu et al. (2008) studied the relationship between pollen morphology and nut yield in 20 chestnut cultivars and have found that the exine ornamentations of the chestnut pollens were different. Chen and Shi (2009) also examined the four chestnut cultivars in Yunnan by scanning electron microscope (SEM) and they found that the sizes of pollens were different among the varieties. Although there are some descriptions of pollen morphology in Castanea, studies of this genus are still limited. While China has about 300 chestnut cultivars (Huang 1998), the differences in chestnut pollen morphological characteristics among species and cultivars have not been well investigated. The purpose of this study was to enrich the knowledge of the pollen morphology characteristics of selected chestnut cultivars and to examine the pollen features in order to develop an additional identification tool of plant materials.

*Author for correspondence: <zoufeng06@126.com>. 


\section{Materials and Methods}

Flowers of 16 chestnut cultivars were used in the study (Table 1). Pollen grains of 16 chestnut cultivars were collected from 6-year-old trees in Central South University of Forestry and Technology Chestnut Orchard (Hunan Province, China) $\left(27^{\circ} 55^{\prime} 30^{\prime \prime} \mathrm{N}, 113^{\circ} 09^{\prime} 50^{\prime \prime} \mathrm{E}\right)$ which is situated approximately at $70 \mathrm{~m}$ above sea level.

Table 1. The list of 16 chestnut cultivars and accessions used in this study.

\begin{tabular}{|c|c|c|c|}
\hline ID & Cultivar name & Pedigree & Origin (Province) \\
\hline A1 & 'Manzhen' & C. henryi & Fujian \\
\hline $\mathrm{A} 2$ & 'Chaizhen' & $"$ & $"$ \\
\hline A3 & 'Houruizi' & $"$ & $"$ \\
\hline A4 & 'Changmangzi' & $"$ & $"$ \\
\hline A5 & 'Chushuhong' & $"$ & $"$ \\
\hline A6 & 'Huangzhen' & $"$ & $"$ \\
\hline A7 & 'Youzhen' & $"$ & $"$ \\
\hline A8 & ‘Tiezhen' & $"$ & $"$ \\
\hline A9 & 'Qianxizaofeng' & C. mollissima & Hebei \\
\hline A10 & 'Yanshanduanzhi' & $"$ & $"$ \\
\hline A11 & 'Zunyu' & $"$ & $"$ \\
\hline $\mathrm{A} 12$ & 'Dabanhong' & $"$ & $"$ \\
\hline A13 & 'Yanlong' & $"$ & $"$ \\
\hline A14 & 'Yanshanzaofeng' & $"$ & $"$ \\
\hline A15 & 'Yankui' & $"$ & $"$ \\
\hline A16 & 'Qianxiwanfeng' & $"$ & $"$ \\
\hline
\end{tabular}

For observation with SEM, the catkins were brought to the laboratory and laid on clean black paper sheets at room temperature until the anthers dehisced (Bryhan and Serdar 2009). Pollen grains were harvested in a clean microcentrifuge tube. The pollens were mounted on SEM stubs, coated with gold-palladium (Hitachi E-1010, Japan), and examined with a scanning electron microscope (Hitachi S-3400N, Japan) (Zou et al. 2013, Candan and İlkay 2015).

For each chestnut cultivar, 30 pollen grains were used to determine the pollen size (Evrenosoğlu and Misirli 2009, Sosa et al. 2012) and the following morphological traits were measured: (1) length of pollen along the polar axis (PL), (2) length of pollen along the equatorial diameter (ED), (3) Length of pollen along the colpus (CL); (4) ratio of polar axis to equatorial diameter $(\mathrm{P} / \mathrm{E}),(5)$ ratio of polar axis to colpus length $(\mathrm{P} / \mathrm{C}),(6)$ ratio of colpus length to equatorial diameter (C/E) (Lee and Kim 2004). Analysis of variance was performed using the SPSS 24.0 software (USA). Mean separations, by DMRT, were applied using the SPSS 24.0 software at $\mathrm{p} \leq 0.05$. Statistical analysis of principal component analysis (PCA) component (Geraci et al. 2012) and matrix of similarity were realized using SPSS software. In addition, taxonomic relationships were analyzed using dendrogram which was constructed on data matrix of taxonomic distance based on unweighted pair group method with arithmetic mean (UPGMA) analysis (Lee et al. 2008). 


\section{Results and Discussion}

Pollen grains of the 16 chestnut cultivars were found to be small in size, tricolporate (with three germinal colpi) and perprolate type. The pollen surface was rugulate. Pole surfaces of the pollen were smooth (Figs 1 and 2).
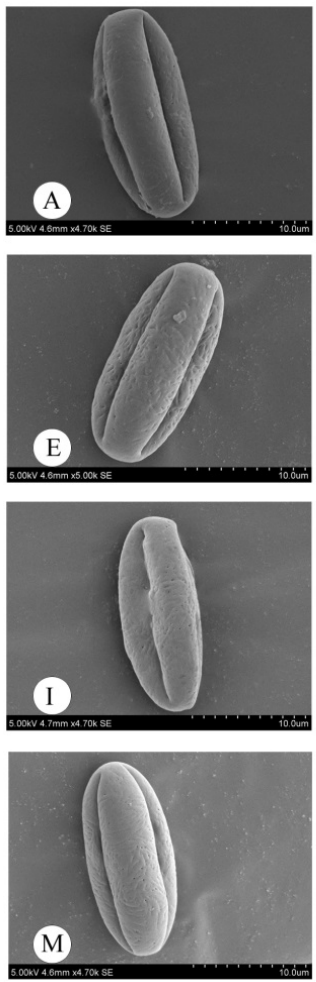
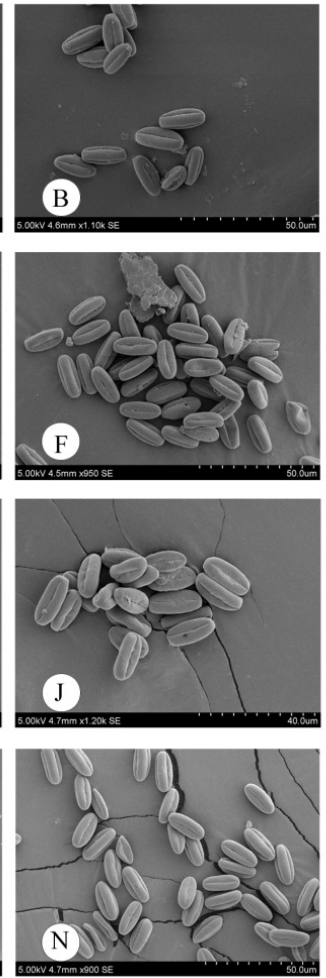
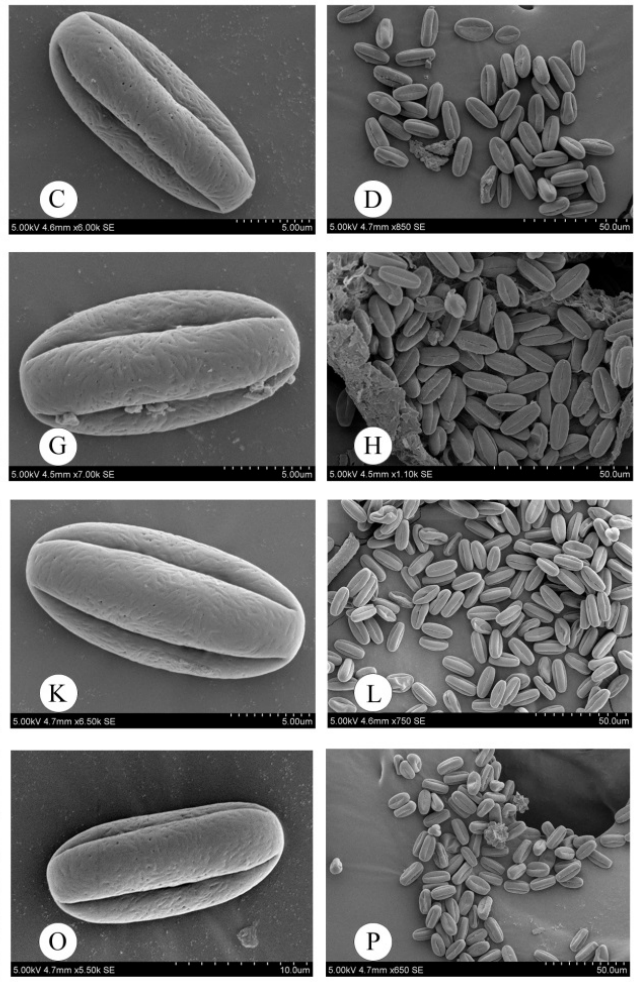

Fig. 1. Scanning electron microscopic photographs of Castanea henryi cultivars. A: Equitorial view of $C$. henryi 'Manzhen'. B: Micrographs of $C$. henryi 'Manzhen' pollen grain. C: Equitorial view of $C$. henryi 'Chaizhen'. D: Micrographs of $C$. henryi 'Chaizhen' pollen grain. E: Equitorial view of $C$. henryi 'Houruizi'. F: Micrographs of $C$. henryi 'Houruizi' pollen grain. G: Equitorial view of $C$. henryi 'Changmangzi'. H: Micrographs of $C$. henryi 'Changmangzi' pollen grain. I: Equitorial view of $C$. henryi 'Chushuhong'. J: Micrographs of $C$. henryi 'Chushuhong' pollen grain. K: Equitorial view of $C$. henryi 'Huangzhen'. L: Micrographs of $C$. henryi 'Huangzhen' pollen grain. M: Equitorial view of $C$. henryi 'Youzhen'. N: Micrographs of $C$. henryi 'Youzhen' pollen grain. O: Equitorial view of $C$. henryi ‘Tiezhen'. P: Micrographs of C. henryi 'Tiezhen' pollen grain.

The longest polar axis length (PL) was found in C. henryi ('Chaizhen') and C. mollissima ('Yankui') $(18.30 \mu \mathrm{m})$, and the shortest was in C. henryi ('Manzhen') $(16.25 \mu \mathrm{m})$. This indicated that chestnut cultivars varied largely in terms of PL (Table 2). Lee and Kim (2004) and Xie et al. (2005) reported that the longest PL of chestnut pollens was $18.63 \mu \mathrm{m}$ (C. spp. Primato) and 18.50 $\mu \mathrm{m}$ (C. mollissima Yangshanyouli), respectively. Present results were almost similar to those of previous studies based on the average PL of the chestnut pollens. Li et al. (1995) examined that the PL of chestnut pollens, collected from Zhejiang province, was $11.80 \mu \mathrm{m}$ (C. mollissima Chunan No. 2) to $15.00 \mu \mathrm{m}$ (C. mollissima Lishui N0. No. 2). Chen and Shi (2009) observed the PL of 'Yunli No. 42' pollens, collected from Yunnan province, was $14.45 \mu \mathrm{m}$. Based on these results, it is obvious that pollen morphology varies with cultivar. 

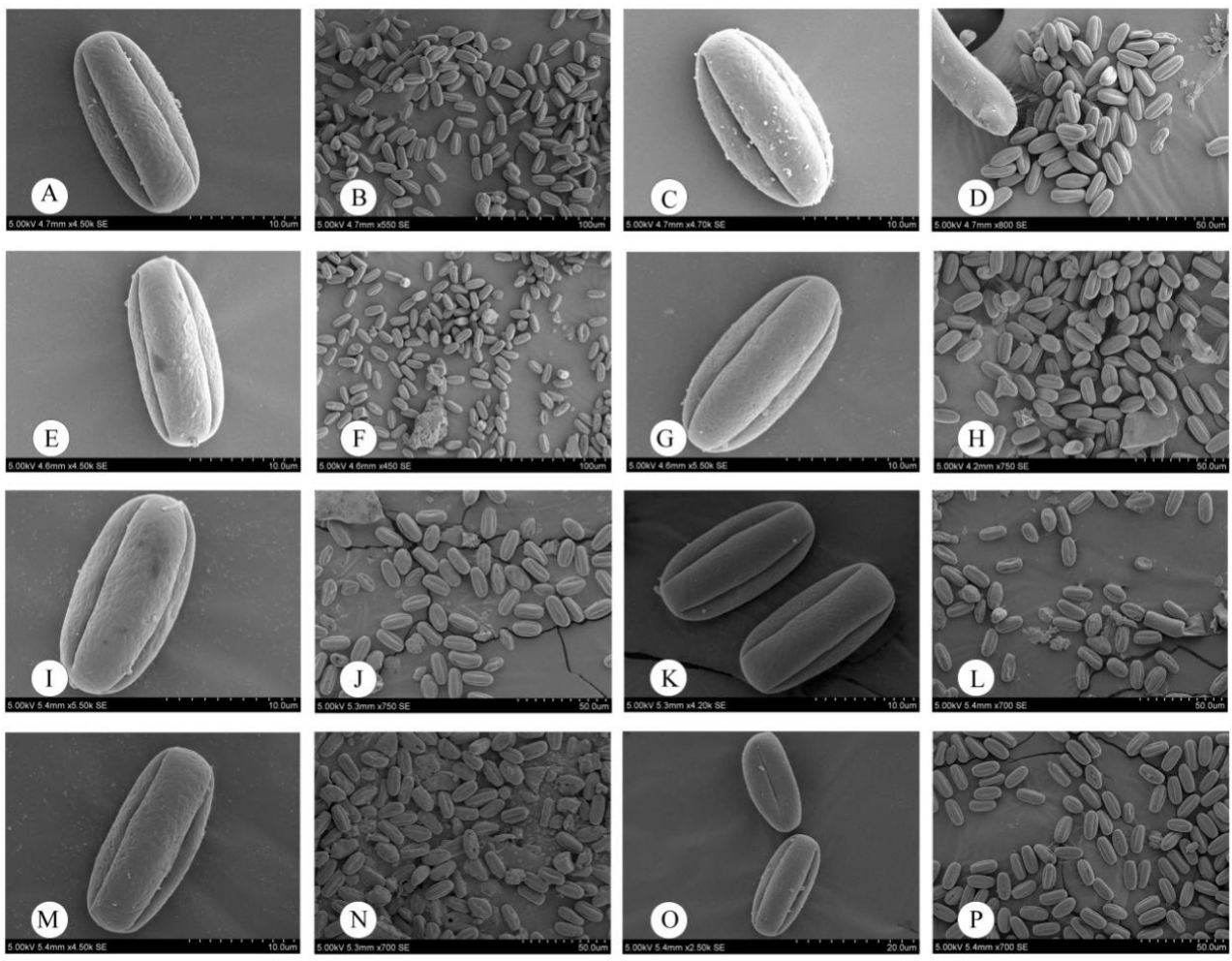

Fig. 2. Scanning electron microscopic photographs of Castanea mollissima cultivars. A: Equitorial view of $C$. mollissima 'Qianxizaofeng'. B: Micrographs of C. mollissima 'Qianxizaofeng' pollen grain. C: Equitorial view of C. mollissima 'Yanshanduanzhi'. D: Micrographs of C. mollissima 'Yanshanduanzhi' pollen grain. E: Equitorial view of $C$. mollissima 'Zunyu'. F: Micrographs of $C$. mollissima 'Zunyu' pollen grain. G: Equitorial view of $C$. mollissima 'Dabanhong'. H: Micrographs of $C$. mollissima 'Dabanhong' pollen grain. I: Equitorial view of $C$. mollissima 'Yanlong'. J: Micrographs of $C$. mollissima 'Yanlong' pollen grain. K: Equitorial view of $C$. mollissima 'Yanshanzaofeng'. L: Micrographs of $C$. mollissima 'Yanshanzaofeng' pollen grain. M: Equitorial view of $C$. mollissima 'Yankui'. N: Micrographs of $C$. mollissima 'Yankui' pollen grain. O: Equitorial view of C. mollissima 'Qianxiwanfeng'. P: Micrographs of C. mollissima 'Qianxiwanfeng' pollen grain.

The mean of ED varied from $6.98 \mu \mathrm{m}(C$. henryi 'Manzhen') to $8.81 \mu \mathrm{m}$ (C. mollissima 'Yankui'). Li et al. (1995) reported almost similar values of 12 chestnut cultivars pollens collected from Zhejiang province, and the values ranged from 5.30 to $8.00 \mu \mathrm{m}$. However, Xie et al. (2005) described that the mean of ED of chestnut pollens, originated from Guangdong province, was $12.12 \mu \mathrm{m}$. Thus, these results demonstrated that ED varied largely with cultivar.

The mean CL ranged from $12.11 \mu \mathrm{m}(C$. henryi 'Tiezhen') to $14.02 \mu \mathrm{m}$ (C. mollissima 'Dabanhong'). Lee and Kim (2004) examined that the CL of chestnut cultivar 'Primato' at 15.61 $\mu \mathrm{m}$ was the longest, whereas the CL of 'Lusenta' at $11.60 \mu \mathrm{m}$ was the shortest among 17 chestnut cultivars. Again, these results showed that CL varied with cultivars. 
Table 2. Pollen morphological traits of the 16 chestnut cultivars. All pollens are perprolate in equatorial view and 3-colporate in aperture type.

\begin{tabular}{lllllll}
\hline ID & PL & ED & CL & P/E & P/C & C/E \\
\hline A1 & $16.25 \mathrm{a}^{\mathrm{z}}$ & $6.98 \mathrm{a}$ & $13.41 \mathrm{cdef}$ & $2.34 \mathrm{e}$ & $1.21 \mathrm{a}$ & $1.93 \mathrm{~g}$ \\
A2 & $18.30 \mathrm{~h}$ & $7.99 \mathrm{cdef}$ & $13.48 \mathrm{cdef}$ & $2.29 \mathrm{e}$ & $1.38 \mathrm{~cd}$ & $1.69 \mathrm{de}$ \\
A3 & $18.06 \mathrm{efgh}$ & $7.88 \mathrm{cde}$ & $13.97 \mathrm{ef}$ & $2.30 \mathrm{e}$ & $1.30 \mathrm{abcd}$ & $1.78 \mathrm{ef}$ \\
A4 & $16.47 \mathrm{ab}$ & $7.25 \mathrm{bc}$ & $13.31 \mathrm{cdef}$ & $2.28 \mathrm{e}$ & $1.25 \mathrm{ab}$ & $1.85 \mathrm{fg}$ \\
A5 & $17.56 \mathrm{defg}$ & $7.80 \mathrm{~cd}$ & $12.97 \mathrm{abcd}$ & $2.25 \mathrm{de}$ & $1.38 \mathrm{bcd}$ & $1.66 \mathrm{bcde}$ \\
A6 & $17.41 \mathrm{cdef}$ & $7.92 \mathrm{cdef}$ & $13.04 \mathrm{abcde}$ & $2.21 \mathrm{cde}$ & $1.36 \mathrm{bcd}$ & $1.66 \mathrm{bcde}$ \\
A7 & $18.26 \mathrm{~h}$ & $8.11 \mathrm{defg}$ & $13.60 \mathrm{cdef}$ & $2.26 \mathrm{de}$ & $1.36 \mathrm{bcd}$ & $1.68 \mathrm{cde}$ \\
A8 & $16.76 \mathrm{abc}$ & $8.29 \mathrm{efg}$ & $12.11 \mathrm{a}$ & $2.03 \mathrm{a}$ & $1.41 \mathrm{~d}$ & $1.46 \mathrm{a}$ \\
A9 & $17.05 \mathrm{bcd}$ & $8.11 \mathrm{defg}$ & $12.33 \mathrm{bc}$ & $2.11 \mathrm{ab}$ & $1.39 \mathrm{~cd}$ & $1.53 \mathrm{ab}$ \\
A10 & $17.51 \mathrm{defg}$ & $7.62 \mathrm{bc}$ & $12.95 \mathrm{abcd}$ & $2.30 \mathrm{e}$ & $1.37 \mathrm{bcd}$ & $1.71 \mathrm{de}$ \\
A11 & $18.11 \mathrm{gh}$ & $8.46 \mathrm{gh}$ & $12.97 \mathrm{abcd}$ & $2.15 \mathrm{abc}$ & $1.42 \mathrm{~d}$ & $1.54 \mathrm{abc}$ \\
A12 & $18.09 \mathrm{fgh}$ & $8.00 \mathrm{cdef}$ & $14.02 \mathrm{f}$ & $2.27 \mathrm{de}$ & $1.31 \mathrm{abcd}$ & $1.76 \mathrm{ef}$ \\
A13 & $17.36 \mathrm{~cd}$ & $8.36 \mathrm{fg}$ & $12.64 \mathrm{abc}$ & $2.08 \mathrm{a}$ & $1.40 \mathrm{~cd}$ & $1.53 \mathrm{ab}$ \\
A14 & $16.56 \mathrm{ab}$ & $8.04 \mathrm{cdefg}$ & $13.10 \mathrm{bcdef}$ & $2.09 \mathrm{a}$ & $1.27 \mathrm{abc}$ & $1.65 \mathrm{bcde}$ \\
A15 & $18.30 \mathrm{~h}$ & $8.81 \mathrm{~h}$ & $13.87 \mathrm{def}$ & $2.09 \mathrm{a}$ & $1.32 \mathrm{abcd}$ & $1.59 \mathrm{abcd}$ \\
A16 & $17.38 \mathrm{cde}$ & $8.28 \mathrm{efg}$ & $12.91 \mathrm{abcd}$ & $2.10 \mathrm{ab}$ & $1.35 \mathrm{bcd}$ & $1.56 \mathrm{abcd}$ \\
\hline
\end{tabular}

PL: Polar axis length; ED: Equatorial-diameter; CL: Colpus length; P/E: PL/ED; P/A: PL /CL and C/E: $\mathrm{CL} / \mathrm{ED} .{ }^{\mathrm{z}}$ Different letters followed means in the same column are significantly different tested by DMRT at $\mathrm{p}$ $\leq 0.05$.

For morphological characteristics of chestnut pollens, there was a large variation in pollen size such as $\mathrm{P} / \mathrm{E}, \mathrm{P} / \mathrm{C}$ and $\mathrm{C} / \mathrm{E}$ ratios among cultivars. The shape of the 16 chestnut pollen grains was mainly perprolate (Evrenosoğlu and Misirli 2009). The mean P/E ratio ranged from 2.03 in $C$. henryi 'Tiezhen' to 2.34 in $C$. henryi 'Manzhen'. Present results agreed with those reported by Tian et al. (2013) for the mean value of $\mathrm{P} / \mathrm{E}$ ratio in four Castanea species. The mean $\mathrm{P} / \mathrm{C}$ ratio ranged from 1.21 to 1.42 , while the mean $\mathrm{C} / \mathrm{E}$ ratio ranged from 1.46 to 1.93 (Table 2). It was found that the results were similar based on the average $\mathrm{P} / \mathrm{C}$ and $\mathrm{C} / \mathrm{E}$ ratios of chestnut pollens observed by Lee and Kim (2004).

Based on the results of principal component analysis of the pollen morphological traits (Table 3), 99.56\% cumulative variance was explained in the principal components 1 to 3 . The first two components showed $79.48 \%$ concluding of length of polar axis and length of equatorial diameter.

The principal component score, associated to each variable on the three principal components (PC), identifies the variables that mostly define them (Tables 3 and 4). The PC1 showing $50.09 \%$ was very high in covariance contribution, which was positively correlated with following variables: $\mathrm{CL}, \mathrm{P} / \mathrm{E}$ ratio and $\mathrm{C} / \mathrm{E}$ ratio. The $\mathrm{PC} 2$ signified $29.39 \%$ of cumulative variance and was positively correlated with $\mathrm{PL}, \mathrm{P} / \mathrm{E}$ ratio, $\mathrm{P} / \mathrm{C}$ ratio and $\mathrm{C} / \mathrm{E}$ ratio. The $\mathrm{PC} 3$ showed $20.08 \%$ of cumulative variance and was positively correlated with all variables except $\mathrm{P} / \mathrm{C}$ ratio. The correlation matrix showed the variables that mostly identified and defined the three principal components (Table 4): PC1 was strongly correlated with C/E (0.98) variable, PC2 with $\mathrm{P} / \mathrm{E}$ (0.91) variable and PC3 with PL (0.82). The projections of the PC loadings defined by the first two principal components allowed to visualize the position of Castanea cultivars as shown in score plot (Fig. 3). 
Table 3. Percentage variance contributions by principal components for the dimension and characteristics of Castanea pollen grains.

\begin{tabular}{cccc}
\hline \multicolumn{4}{c}{ Total variance explained } \\
\hline Principal components & Eigen value & Variance $(\%)$ & Cumulative variance $(\%)$ \\
\hline 1 & 3.01 & 50.09 & 50.09 \\
2 & 1.76 & 29.39 & 79.48 \\
3 & 1.21 & 20.08 & 99.56 \\
4 & 0.01 & 0.26 & 99.82 \\
5 & 0.01 & 0.14 & 99.96 \\
6 & 0.00 & 0.04 & 100.00 \\
\hline
\end{tabular}

Table 4. Principal component analysis loadings and contributions of the principal components.

\begin{tabular}{cccc}
\hline \multicolumn{2}{c}{ PCA loadings } & \\
\hline Variables & PC 1 & PC 2 & PC 3 \\
\hline PL & -0.41 & 0.39 & 0.82 \\
ED & -0.67 & -0.61 & 0.42 \\
CL & 0.74 & -0.38 & 0.55 \\
P/E & 0.38 & 0.91 & 0.17 \\
P/C & -0.85 & 0.51 & -0.05 \\
C/E & 0.98 & 0.13 & 0.11 \\
\hline
\end{tabular}

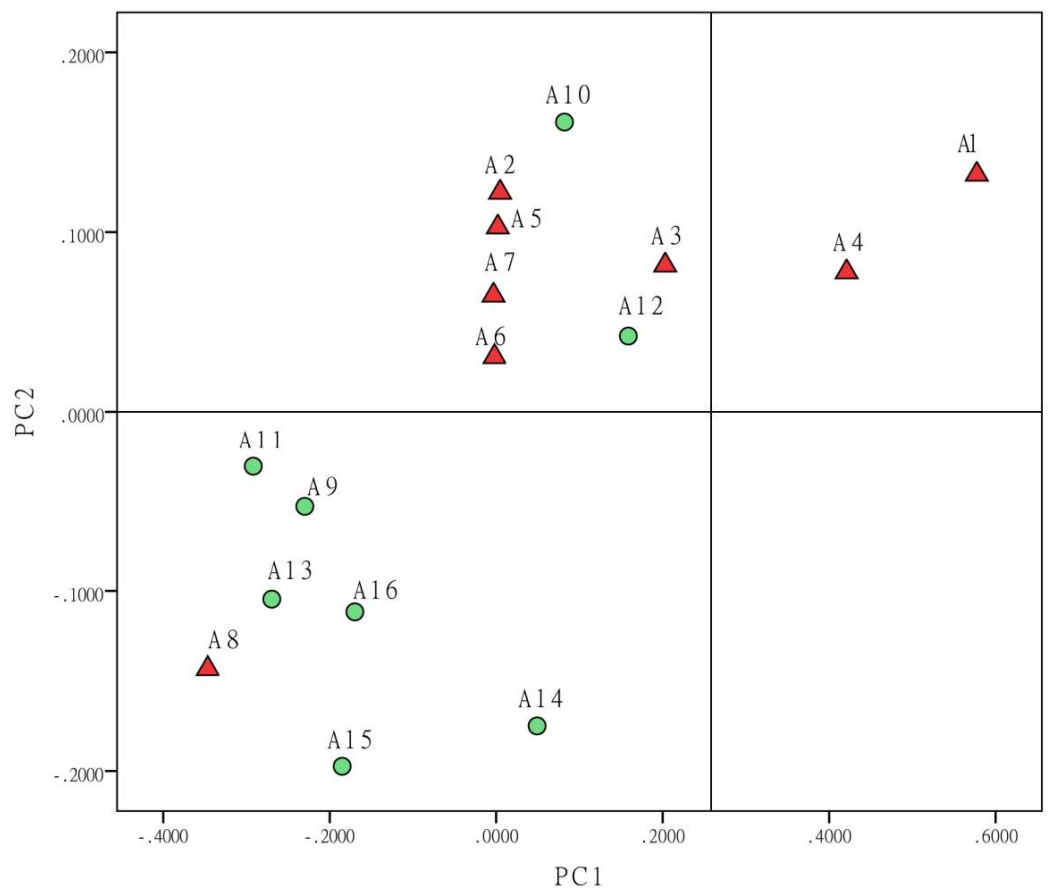

Fig. 3. Scatter diagram of Castanea cultivars in the first and second principal components. 


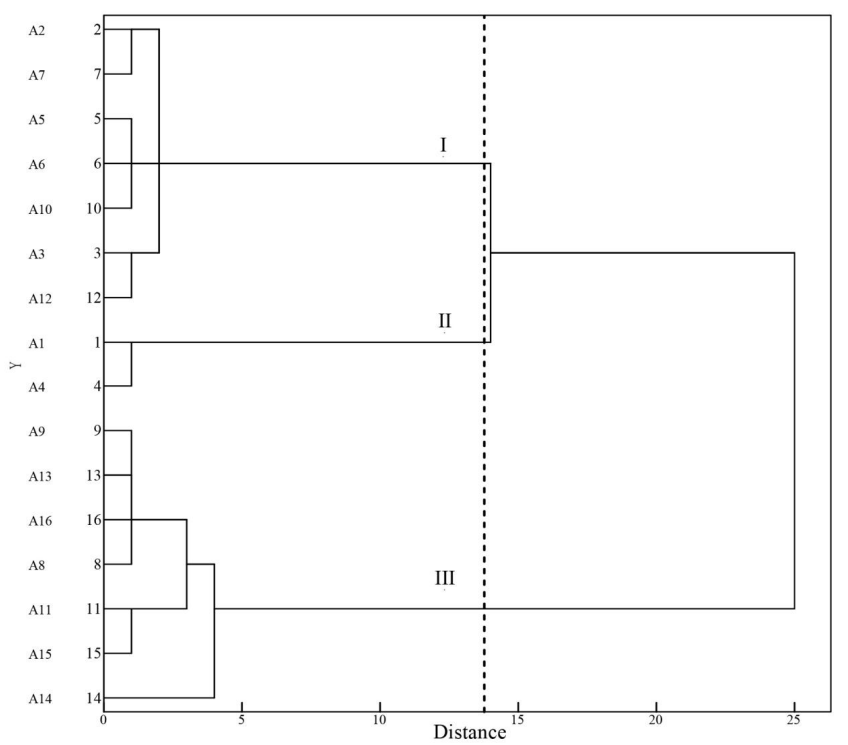

Fig. 4. UPGMA tree of Castanea cultivars constructed on the basis of the Euclidean distance matrix. Refer Table 1 for cultivars ID.

In addition, the differences among the samples analyzed based on parameters measured on their pollen grains, were verified by the cluster analysis using UPGMA algorithm on the basis of Euclidean distance matrix. The analysis of the UPGMA tree (Fig. 4) revealed three principal groups of morphological similarity: (i) $C$. henryi cv. Chaizhen (A2), C. henryi cv. Youzhen (A7), $C$. henryi cv. Chushuhong (A5), C. henryi cv. Huangzhen (A6), C. mollissima cv. Yanshanduanzhi (A10), C. henryi cv. Houruizi (A3) and C. mollissima cv. Dabanhong (A12); (ii) C. henryi cv. Manzhen and Changmangzi (A1 and A4); (iii) C. mollissima cv. Qianxizaofeng (A9), $C$. mollissima cv. Yanlong (A13), C. mollissima cv. Qianxiwanfeng (A16), C. henryi cv. Tiezhen (A8), C. mollissima cv. Zunyu (A11), C. mollissima cv. Yankui (A15) and Yanshanzaofeng (A14). The cluster analysis showed a great morphological affinity among sixteen cultivars, while the two cultivars of $C$. henryi (Manzhen and Changmangzi) were different due to the small-size pollen grains $(16.25-16.47 \mu \mathrm{m} \times 6.98-7.25 \mu \mathrm{m})$.

\section{Acknowledgements}

The project was partly supported by the Key Research and Development Program of Hunan Province (Grant No. 2018NK2043), the Hunan Provincial Natural Science Foundation of China (No.2018JJ3870) and the National Natural Science Foundation of China (No.31500554).

\section{References}

Bounous G and Marinoni DT 2005. Chestnut: botany, horticulture and utilization. Horticultural Reviews 31: 291-347.

Bryhan N and Serdar U 2009. In vitro pollen germination and tube growth of some European chestnut genotypes (Castanea sativa Mill.). Fruits 64(3):157-165.

Candan F and İkay ÖÇ 2015. Pollen micromorphology of four taxa of Anemone coronaria L. from western Turkey. Bangladesh J. Bot. 44(1): 31-36. 
Chen JJ and Shi ZG 2009. Studies on pollen morphology, germination rate and fruit characteristics of Castanea mollissima in Yunnan. J. Central South Univ. Fores. Tech. 29(6): 152-155 (in Chinese with abstract in English).

Evrenosoğlu Y and Misirli A 2009. Investigations on the pollen morphology of some fruit species. Turk. J. Agric. For. 33: 181-190.

Fan XM, Yuan DY, Tang J, Tian XM, Zhang L, Zou F and Tan XF 2015. Sporogenesis and gametogensis in Chinese chinquapin (Castanea henryi (Skam) Rehder \& Wilson) and their systematic implications. Trees 29: 1713-1723.

Geraci A, Polizzano V, Marino P and Schicchi R 2012. Investigation on the pollen morphology of traditional cultivars of Prunus species in Sicily. Acta Soc. Botanic. Polon. 81(3): 175-184.

Huang HW 1998. Review of current research of the world Castanea species and importance of germplasm conservation of China native Castanea species. J. Wuhan Bot. Res. 16(2): 171-176. (in Chinese with English abstract).

Lee U and Kim JM 2004. A consideration on the pollen morphology of chestnut (Castanea spp.) by using scanning electron microscope (SEM). J. Korean For. Soc. 93(1):10-15 (in Korean with in abstract in English).

Lee U, Jung MS, Lee MH, Kang KN, Hyun JO and Kwon YH 2008. A consideration on the pollen morphology of walnut trees (Juglans spp.) by using scanning electron microscope (SEM). Korean J. Apicul. 23(2): 139-145.

Li J, Wang W, Zhang HW and Ying TL 1995. Main botanical and pollen characteristics of partical Chinese chestnut clones. J. Zhejiang For. Coll. 12(2): 121-127 (in Chinese with abstract in English).

Liu ZY, LiLS, Liu ZF and Chen BG 2008. Relationship between pollen morphology and nut yield in chestnut. Nonwood For. Res. 26(4): 57-62 (in Chinese with abstract in English).

Mckay, JW 1942. Self-sterility in the Chinese chestnut (Castanea mollissima). Proc. Amer. Soc. Hort. Sci.41: 156-161.

Mert C 2010. Anther and pollen morphology and anatomy in walnut (Juglans regia L.). Hort. Sci. 45(5): 757-760.

Mert C and Soylu A 2006. Flower and stamen structures of male-fertile and male-sterile chestnut (Castanea sativa Mill.) cultivars. J. Amer. Soc. Hort. Sci. 131(6): 752-759.

Mert C and Soylu A 2007. Morphology and anatomy of pollen grains from male-fertile and male-sterile cultivars of chestnut (Castanea sativa Mill.). J. Hort. Sci. Biotech. 82(3): 474-480.

Sosa MLM, Pansersi AF and Salgado CR 2012. Pollen morphology of eight species of Stemodia (Plantaginaceae) from South America. Polynol. 36(1): 1-9.

Tian SL, Sun XL, Shen GN and Xu L 2013. Characteristics of Castanea pollen germination in China. Nonwood For. Res. 31(1): 75-80 (in Chinese with abstract in English).

Xie ZF, Xie ZS and Zeng SC 2005. The pollen morphology and sprouting characteristics of 6 Chinese chestnut varieties. J. Fujian College of For. 25(4): 344-348 (in Chinese with in abstract in English i).

Xiong H, Sun H, Zou F, Fan XM, Niu GH, Yuan DY 2018. Micropropagation of chinquapin (Castanea henryi) using axillary shoots and cotyledonary nodes. HortScience 53(10): 1482-1486.

Zou F, Guo SJ, Xiong H, Xie P, Lv WJ and Li GH 2013. A morphological and histological characterization of male flower in chestnut (Castanea) cultivar 'Yanshanzaofeng'. Adv. J. Food Sci. Tech. 5(9): 1192-1197.

Zou F, Guo SJ, Xie P, Xiong H, Lv WJ and Li GH 2014. Megasporogenesis and development of female gametophyte in Chinese chestnut (Castanea mollissima) cultivar 'Yanshanzaofeng'. Int. J. Agr. Biol. 16(5): 1001-1005. 